\title{
Crescimento e produtividade do milho híbrido fertilizado com urina humana na agricultura de pequeno porte
}

O presente trabalho teve como objetivo analisar o comportamento do milho híbrido em termos de crescimento e produtividade quando fertilizado com urin humana. O delineamento experimental utilizado foi o de blocos ao acaso com cinco tratamentos. Os tratamentos aplicados foram: T1 - água bruta e adubação orgânica; T2 - água bruta e adubação química e orgânica, T3 - água bruta e urina na dose recomendada; T4 - água bruta e metade da dose de urina recomendada; T5 - água bruta e 1,5 da dose de urina recomendada. O volume de urina aplicado foi calculado a partir da demanda nutricional da cultura do milho e da concentração de nitrogênio na urina humana resultando no valor 1,0 litro por metro linear para o tratamento - T3. A área cultivada com milho foi irrigada por gotejamento, sistema selecionado por ser um dos mais utilizados pelos agricultores rurais. Com relação às variáveis, altura da planta e índice de espiga não houve diferença significativa $(p>0,05)$ quando se comparou os tratamentos estudados. Por outro lado, os resultados da pesquisa indicaram que o peso das espigas variou conforme o tipo de adubação (química ou urina) e quanto ao volume de urina aplicado, ocorrendo efeito entre aplicar urina na taxa de 1,5 ou 1 e aplicar urina na taxa de 0,5 ou adubo químico $(p<0,05)$. A urina se mostrou como um potencial praguicida à lagarta-do-cartucho (Spodoptera Frugiperda), pois nenhuma das plantas que recebeu este tratamento foi acometida por tal praga, a qual prejudicou a produtividade do tratamento com NPKS. Do ponto de vista experimental, o presente estudo evidenciou resultados promissores acerca da utilização de urina humana na fertilização de Zea mays.

Palavras-chave: Águas Amarelas; Cultura Alimentícia; Reúso; Saneamento Focado Em Recursos; Biofertilizante.

\section{Growth and yield of hybrid corn fertilized with human urine in small agriculture}

\begin{abstract}
This research aimed to evaluate the response of hybrid corn in terms of yield and growth when fertilized with human urine. The design of the experiment was randomized blocks with five treatments. The treatments were: $\mathrm{T} 1$ - raw water and organic manure; $\mathrm{T} 2$ - raw water, organic manure and chemical fertilization, $\mathrm{T} 3$ raw water and urine at the recommended dose; T4 - raw water and 0,5 urine of the recommended dose and T5 - raw water and 1,5 urine of the recommended dose. The volume of urine applied was determined from the nutritional demand of hybrid corn and the concentration of nitrogen in human urine resulting in 1,0 liter per linear meter for treatment - T3. The irrigation method chosen was drip irrigation, selected for being one of the most used by rural farmers. Concerning plant height and ear index, there was no significant difference $(p>0,05)$ when comparing the treatments applied. The weight of spikes varied according to the type of fertilizer (chemical or urine) and also to the volume of urine applied, where it showed difference between application of urine on the rate of 1,5 or 1,0 and application of urine on the rate of 0,5 or organic manure $(p<0,05)$. The urine showed to be a potential pesticide to Spodoptera frugiperda, because none of the plants that received this treatment was affected by this plague, which adversely affected the productivity of treatment with NPKS. From the experimental point of view, this study showed promising results on the use of human urine to fertilize Zea mays.
\end{abstract}

Keywords: Yellow Water; Food Crop; Reuse; Ecological Sanitation; Bio-Fertilizer.

Topic: Engenharia Sanitária

Reviewed anonymously in the process of blind peer.
Received: 14/12/2017

Approved: 24/01/2018
Márcio Pessoa Botto (iD)

Universidade de Fortaleza, Brasil

http://lattes.cnpq.br/6581806275313386

http://orcid.org/0000-0003-2810-6504

marciobotto@yahoo.com

Lucas Falcão Muniz (iD)

Universidade Federal do Ceará, Brasil

http://lattes.cnpq.br/5366195836235950

http://orcid.org/0000-0002-4314-4421

lucasfalcaomuniz@gmail.com

Bonerges Freire de Aquino

Universidade de Fortaleza, Brasil

aquino@ufc.br
André Bezerra dos Santos

Universidade Federal do Ceará, Brasi

http://lattes.cnpq.br/3626519258208111

andre23@ufc.br
Referencing this:

BOTTO, M. P.; MUNIZ, L. F.; AQUINO, B. F.; SANTOS, A. B.. Crescimento e produtividade do milho híbrido fertilizado com urina humana na agricultura de pequeno porte. Revista Ibero Americana de Ciências Ambientais, v.9, n.2, p.195-206, 2018. DOI: http://doi.org/10.6008/CBPC2179-6858.2018.002.0017 


\section{INTRODUÇÃO}

Diversos estudos apontam para a potencialidade do uso da urina humana na agricultura, por ser um líquido que contém nitrogênio, fosfato e potássio na forma dissolvida em concentrações razoáveis para atender as demandas nutricionais das culturas fertilizadas (JÖNSSON et al., 2004; KARAK et al., 2011; RICHERT et al., 2010). As principais culturas pesquisadas até então foram: cevada (RODHE et al., 2004), milho (KASSA et al., 2010), pepino (HEINONEN-TANSKI et al., 2007), trigo (GANROT et al., 2007); tomate (PRADHAN et al., 2009); beterraba (PRADHAN et al., 2007); sorgo (GERMER et al., 2011); quiabo; espinafre; pimentão (SHRESTHA et al., 2013).

Vêm se reportando na atualidade que o uso da urina, de forma adequada, na agricultura, poderia beneficiar milhões de pessoas que vivem nas regiões tropicais e semitropicais por meio do aumento da produtividade de culturas alimentícias, seja em pequenas plantações ou mesmo no cultivo destas em jarros nas próprias residências (HEINONEN-TANSKI et al., 2007). A urina pode ser considerada uma ótima alternativa para incrementar a produtividade de vegetais e frutas cultivadas por agricultores de subsistências, uma vez que os fertilizantes minerais não são considerados por estes como uma opção vantajosa, devido ao seu custo elevado (MORGAN, 2003).

Considerando que o agricultor de subsistência não possui recursos suficientes para a compra de fertilizantes, a Organização Mundial de Saúde (OMS) afirma que o uso de excretas humanas na agricultura pode afetar positivamente a pobreza em diversas formas, dentre elas: a redução da desnutrição, por meio da melhora da segurança alimentar e enriquecimento nutricional, e o aumento dos rendimentos a partir da venda da colheita excedente (WHO, 2006).

Dentre os exemplos práticos de aplicação da urina em escala real, destacam-se casos na China, cidade de Dongsheng; na Índia, cidades de Tamilnadu, Karnataka e Bangalore; na Suécia, cidades de Vaxholm e Uppsala; na Etiópia; no México; cidades do México e Tepoztlán; no Quênia, em Nakuru; na Tanzânia, cidade de Arusha; em Uganda, cidade de Kitgum; em Mali, na Bolívia, cidade de El Alto; no Perú, cidade de Juliaca; na Alemanha; no Nepal; no Vietnam e na África do Sul (KASSA et al., 2010; RICHERT et al., 2010; JÖNSSON et al., 2004; SHAW, 2010). De acordo com as estimativas da GIZ, em 2012, foram mais de 3.110 .000 usuários de tecnologias de saneamento sustentáveis, dentre os quais 1.710 .000 utilizam os sanitários separadores de excretas (GIZ, 2012).

O milho, cultura pesquisada neste estudo, é cultivado em praticamente todo o território brasileiro, sendo que $90 \%$ da produção fica concentrada nas regiões Sul $(40,76 \%$ da produção), Sudeste $(19,13 \%$ da produção) e Centro-Oeste (30,18\% da produção) (CRUZ, 2011). Conforme Castro (2010), essa cultura se destaca por estar entre os cereais mais produzidos no Brasil, possuindo elevada importância no Nordeste, principalmente, visando às produções de milho verde e de grãos. O consumo de milho no estado 'verde' sempre foi uma tradição no Brasil e hoje é comum a comercialização tanto do milho verde como de seus produtos (pamonha, canjica, suco etc.) durante o ano todo, nos principais centros consumidores (PEREIRA FILHO, 2002). Apesar de não ter uma participação muito grande no uso de milho em grão, a alimentação 
humana, com derivados de milho, constitui fator importante de uso desse cereal em regiões de baixa renda (DUARTE et al., 2010; SILVA et al., 2006).

O principal objetivo deste estudo foi avaliar a possibilidade de uso da urina como fertilizante natural na produção de cultura alimentícia (milho híbrido), por meio da análise de variáveis de produção e de crescimento. Enfatiza-se a importância da pesquisa quanto à particularidade dos experimentos realizados em campo, a fim de coletar dados que representem da melhor forma a realidade do agricultor. Caso a pesquisa fosse realizada em casa de vegetação (experimentos em jarro) não seria possível obter valores de produtividade do milho a partir das reais condições ambientais (radiação solar, precipitação, temperatura, umidade etc.) e das inúmeras variáveis que afetam diretamente o plantio de campo.

\section{MATERIAIS E MÉTODOS}

O experimento foi conduzido em uma área anexa à estação de tratamento de esgotos do município de Aquiraz, na região metropolitana de Fortaleza, Ceará, Brasil, pertencente à Companhia de Água e Esgoto do Ceará - CAGECE, cujas coordenadas geográficas de referência são: $3^{\circ} 54^{\prime} 05^{\prime \prime}$ de Latitude (S), 38 $23^{\circ} 28^{\prime \prime}$ de Longitude (W) e 14,2 m de altitude. O clima da região é caracterizado, segundo a classificação de Köppen, como sendo do tipo Aw, tropical (inverno seco e verão úmido), clima quente e úmido com chuvas de verão, durante os meses de janeiro a maio. As temperaturas médias mensais estão entre $26{ }^{\circ} \mathrm{C}$ e $28{ }^{\circ} \mathrm{C}$ e a pluviosidade média anual é 1.379,9 mm (BRASIL, 1973).

O delineamento experimental utilizado foi de blocos ao acaso com cinco tratamentos e duas repetições. A área de plantio, de 38,4 m² (3,2 m x $12 \mathrm{~m}$ ), foi subdividida em dois blocos medindo 19,2 $\mathrm{m}^{2}$ $(3,2 \mathrm{~m} \times 6 \mathrm{~m})$, com espaçamento entre plantas de $0,20 \mathrm{~m}$ e espaçamento entre linhas de $0,80 \mathrm{~m}$. Foram reservadas ainda as linhas laterais e uma linha central separando os blocos. Cada bloco continha 6 linhas de plantio com 16 plantas, onde os tratamentos eram aplicados em um total de 192 plantas na área de plantio.

Conforme visualizado na tabela 1, foram estudados 5 tipos de tratamento: T1 - irrigação com água bruta e adubação de fundação com esterco curtido; T2 - irrigação com água bruta e adubação de fundação e de cobertura (NPKS + esterco curtido); T3 - irrigação com água bruta e dose de urina recomendada; T4 irrigação com água bruta e metade da dose de urina recomendada; T5 - irrigação com água bruta e 1,5 da dose de urina recomendada.

Tabela 1: Tratamentos aplicados no cultivo do milho.

\begin{tabular}{|l|l|l|}
\hline Tratamento & Descrição & Tipo de fertilizante \\
\hline T1 & $\begin{array}{l}\text { Controle: adubação } \\
\text { orgânica }\end{array}$ & Orgânico (Esterco curtido) \\
\hline T2 & Fertilizante comercial & $\begin{array}{l}\text { Orgânico (Esterco curtido) e Químico (Uréia, Superfosfato simples, cloreto de } \\
\text { potássio e FTE BR12) }\end{array}$ \\
\hline T3 & Urina & Natural (urina) \\
\hline T4 & Metade da dose de urina & Natural (urina) \\
\hline T5 & 1,5 da dose de urina & Natural (urina) \\
\hline
\end{tabular}

De posse dos resultados da análise química do solo realizou-se a recomendação de adubação para a cultura do milho. No tratamento controle (T1), utilizou-se apenas o adubo orgânico. Os valores aplicados de 
adubo químico no tratamento 2 (T2) foram os seguintes: $60 \mathrm{~kg} \cdot \mathrm{ha}^{-1}$ de nitrogênio, correspondendo a 10 gramas de ureia por metro linear; $90 \mathrm{~kg} \cdot \mathrm{ha}^{-1}$ de fósforo, representado por 40 gramas de superfosfato simples, e $45 \mathrm{~kg} \cdot \mathrm{ha}^{-1}$ de potássio, ou seja, 6 gramas de cloreto de potássio. Quanto ao adubo orgânico, foi aplicado esterco curtido na taxa de 5,0 litros por metro linear em todos os tratamentos. Todos os cinco tratamentos utilizados nesta pesquisa receberam água bruta de poço como fonte hídrica. A caracterização desta água encontra-se descrita na tabela 2.

Tabela 2: Características físico-químicas da água utilizada na irrigação do milho.

\begin{tabular}{|c|c|c|c|}
\hline Parâmetros & Análise & Unidade & Água Bruta \\
\hline Físico & Temperatura & $\stackrel{\circ}{\circ}$ & 28,0 \\
\hline \multirow{13}{*}{ Químico } & $\mathrm{pH}$ & & 6,8 \\
\hline & Condutividade & $\mu \mathrm{S} . \mathrm{cm}-1$ & 328,0 \\
\hline & Alcalinidade & mgCaCO3.L-1 & 28,0 \\
\hline & Amônia & mgNH3.L-1 & 0,4 \\
\hline & Nitrato & mg.L-1 & $<0,5$ \\
\hline & Norg & mg.L-1 & 0,6 \\
\hline & Fósforo & mg.L-1 & 0,3 \\
\hline & $\mathrm{DQO}$ & mgO2.L-1 & 46 \\
\hline & Cloreto & mg-Cl.L-1 & 40,0 \\
\hline & Sódio & mg.L-1 & 35,0 \\
\hline & Potássio & mg.L-1 & 5,0 \\
\hline & Cálcio & mg.L-1 & 5,2 \\
\hline & Ferro & mg.L-1 & 0,1 \\
\hline
\end{tabular}

Com a caracterização físico-química da urina, foi possível calcular o volume de urina a ser aplicado por metro linear, a partir da demanda nutricional da cultura, constituindo de $4,8 \mathrm{gN} \mathrm{mL}^{-1}$, ou $60 \mathrm{~kg} \cdot \mathrm{ha}^{-1}$. A partir da concentração de $5.638,5 \mathrm{mgN} . \mathrm{L}^{-1}$ e adotando uma perda por volatilização da amônia igual a $25 \%$ no momento da aplicação, o volume determinado foi 1,06 litros por metro linear, e arredondado, por conveniência, para 1,0 litro/metro linear em T3. A área cultivada com milho foi irrigada por gotejamento, sistema selecionado por ser um dos mais utilizados pelos agricultores rurais. Os gotejadores possuíam a vazão de 2,2 L.h h $^{-1}$ O tempo real de irrigação por turno de rega de um dia foi de aproximadamente 1 hora, definido a partir do estudo de evaporação, tendo como base de dados o tanque classe A instalado no local. Testou-se a cultivar milho híbrido produzido na fazenda de pesquisa da Universidade Federal do Ceará em Pentecoste. As linhas foram abertas com profundidade média de $15 \mathrm{~cm}$, adicionados o adubo orgânico e o químico de acordo com a demanda nutricional do milho, cobertos com 5 a $10 \mathrm{~cm}$ de solo e, logo então, distribuídas 30 sementes em cada linha. Procedeu-se um desbaste depois de 15 dias da germinação.

A colheita foi realizada de forma manual após 90 dias da germinação. Os sabugos de milho foram colhidos e separados por tratamentos e blocos, e depois encaminhados ao Laboratório de Saneamento (Labosan) do DEHA/UFC para pesagem e medição do comprimento e diâmetro. O comprimento foi medido por meio de trena, e o diâmetro com um paquímetro digital. Foram avaliadas as seguintes características quantitativas: altura da planta, índice de espigas, diâmetro da espiga sem palha, comprimento da espiga sem palha, peso e produtividade das espigas.

As variáveis avaliadas foram submetidas à análise de variância (ANOVA), pelo teste $F$ a um nível de significância de 1 a 5\% e análise de regressão em função do tratamento estudado. Quando verificado efeito 
significativo na análise da variância, as médias obtidas nos diferentes tratamentos foram comparadas pelo

Teste Scott e Knott a um nível de significância de 5\%. As análises estatísticas foram efetuadas empregandose o software SISVAR, versão 5.3 (Build 77), desenvolvido no Departamento de Ciências Exatas da Universidade Federal de Lavras (UFLA).

\section{RESULTADOS}

Na tabela 3 estão apresentados os resultados das médias da altura da planta e índice das espigas, em que os tratamentos com urina (T5, T4 e T3) forneceram valores próximos ao tratamento com fertilizante químico (T2). Médias seguidas de letras iguais nas colunas não diferem estatisticamente entre si pelo teste de Scott-knott a $5 \%$ de probabilidade.

Tabela 3: Médias da altura da planta e índices de espigas em função dos tratamentos pesquisados.

\begin{tabular}{|l|l|l|}
\hline Tratamentos & Altura da planta $(\mathbf{c m})$ & Índice de espigas \\
\hline T1 & $129,78 a$ & $0,99 a$ \\
\hline T2 & $158,32 a$ & $1,25 a$ \\
\hline T3 & $144,12 a$ & $0,97 a$ \\
\hline T4 & $140,36 a$ & $1,03 a$ \\
\hline T5 & $151,18 a$ & $0,97 a$ \\
\hline
\end{tabular}

Com relação aos parâmetros diâmetro, comprimento e peso das espigas despalhadas (tabela 4), o tratamento 5 (1,5 vezes a dose de urina recomendada) alcançou valores superiores aos demais tratamentos, demonstrando a possibilidade do uso da urina como fertilizante. Médias seguidas de letras iguais nas colunas não diferem estatisticamente entre si pelo teste de Scott-knott a 5\% de probabilidade.

Tabela 4: Médias do diâmetro, comprimento e peso das espigas despalhadas em função dos tratamentos pesquisados.

\begin{tabular}{|l|l|l|}
\hline Tratamentos & Diâmetro da espiga $\mathbf{( m m})$ & Comprimento da espiga (cm) \\
\hline T1 & $34,59 a$ & $13,42 \mathrm{a}$ \\
\hline T2 & $40,69 \mathrm{~b}$ & $14,95 \mathrm{~b}$ \\
\hline T3 & $40,96 \mathrm{~b}$ & $15,29 \mathrm{~b}$ \\
\hline T4 & $42,93 \mathrm{~b}$ & $14,80 \mathrm{~b}$ \\
\hline T5 & $44,23 \mathrm{~b}$ & $16,46 \mathrm{~b}$ \\
\hline
\end{tabular}

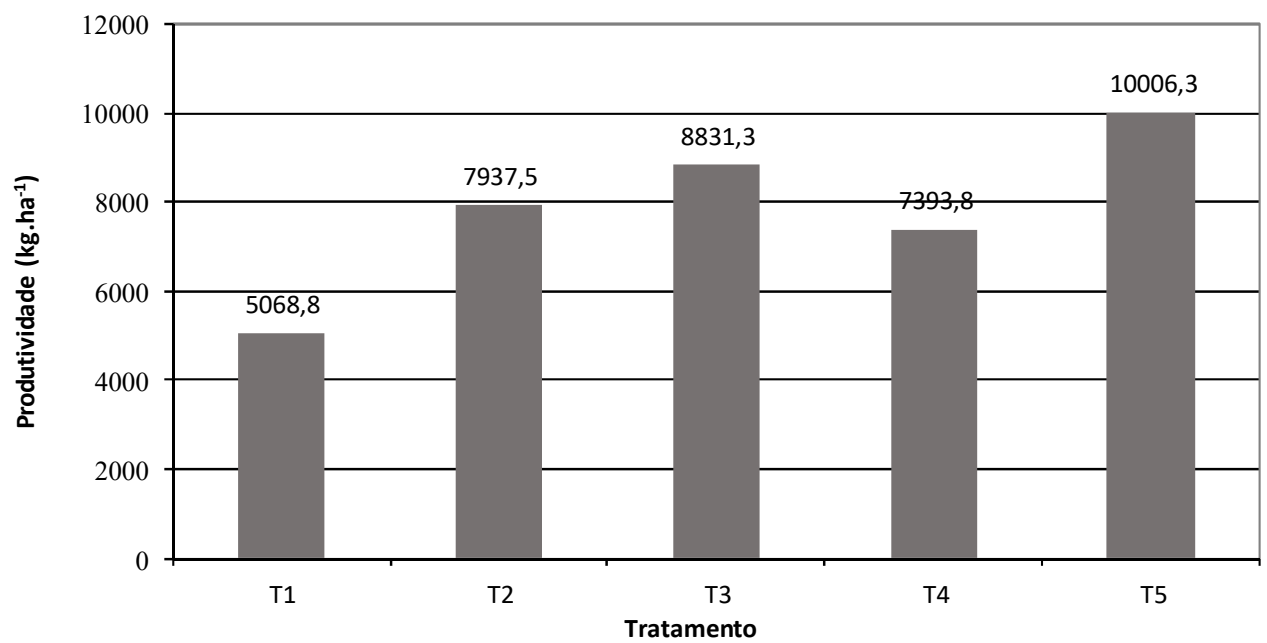

Figura 1: Valores de produtividade, em kg.ha-1, das espigas de milho despalhadas para os diferentes tratamentos (T1 adubo orgânico; T2 - fertilizante químico; T3 - urina; T4 - 0,5 da dose de urina; T5 - 1,5 da dose de urina). 
Na figura 1, é possível verificar os valores do peso da espiga de milho, para cada tratamento, extrapolados em termos de produtividade $\left(\mathrm{kg}_{\mathrm{h}} \mathrm{ha}^{-1}\right)$. Dentre os tratamentos utilizados, a fertilização com 1,5 vezes a dose de urina recomendada proporcionou a melhor produtividade em peso de espigas de milho, com diferenças relativas aos demais tratamentos em: 49,3; 20,7; 11,7 e 26,1\%, respectivamente, para T1; T2; T3 e T4. Como era de se esperar T1, ou seja, o tratamento controle alcançou o menor peso médio entre os demais.

\section{DISCUSSÃO}

Analisando os valores de altura da planta, verificou-se um maior crescimento para T2 (fertilização química), o qual proporcionou a média de 158,3 cm aos 90 dias após semeadura (DAS), valor superior à T1 (adubação orgânica); T3 (dose de urina recomendada); T4 (metade da dose de urina recomendada) e T5 (1,5 vezes a dose de urina recomendada) em: 18,0; 8,8; 11,4 e 4,5\%, respectivamente. Ainda assim, estes resultados não representaram efeitos expressivos $(p=0,079>0,05)$, podendo-se inferir que a altura da planta é a mesma quando se utiliza adubação orgânica, adubação química e adubação com urina, variando as taxas para menos e mais $50 \%$ da dose recomendada (tabela 3 ).

As alturas médias das plantas foram equivalentes ou inferiores aos resultados obtidos por pesquisadores que trabalharam tanto com fertilização química, orgânica ou com água de reuso. Como exemplo, Tozetti et al. (2004) avaliando o crescimento de diferentes progênies de milho na presença e ausência de adubo, encontraram valores médios de altura da planta entre 147,5 e 177,4 cm para as progênies sem adubo e entre 166 e 204 cm, para aqueles com adubação orgânica. Verifica-se que a menor média da altura da planta com adubação foi superior ao maior resultado obtido nesta pesquisa; devido principalmente, ao fato de que o híbrido simples utilizado nesta pesquisa possui características de superprecocidade, com altura média da planta, significativamente, menor quando comparada a outros híbridos e variedades.

Por outro lado, conforme Almeida et al. (2000), atualmente, a menor altura de planta tem sido um caractere desejável entre os produtores de milho por permitir cultivos em maiores densidades e maior eficiência na colheita, ao mesmo tempo em que reduz problemas relacionados com o acamamento e o quebramento de plantas antes do ponto de colheita (KAPPES, 2010), comumente evidenciado com plantas de porte elevado. A arquitetura de planta compacta facilita a penetração de radiação solar no interior da comunidade, até mesmo em lavouras instaladas com estandes adensados (MARCHÃO et al., 2005).

A altura da planta se comportou de forma linear quando se incorporou $50 \%$ a mais de urina com um coeficiente $\left(R^{2}\right)$ igual a 0,969, obedecendo à equação: $y=1,8033 x+134,4$. Verifica-se, portanto, que quanto maior a dose, maior é a altura da planta. Ressalta-se, que a dosagem máxima utilizada foi 1,5 vezes a dose

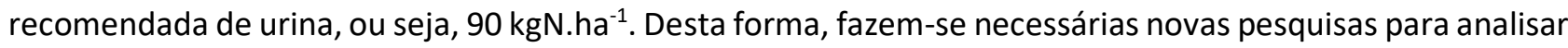
o crescimento e o desenvolvimento da planta aplicando doses mais altas. Deve-se, ainda, levar em consideração o fator da volatilização da amônia durante o manuseio e o transporte da urina.

O maior índice de espiga foi 1,25 para T2, porém com valores próximos aos demais tratamentos. A maior diferença foi 0,28 espigas por planta entre T2 e T5. Em todos os tratamentos, os índices situaram-se 
próximos a 1 (um), valor este comumente encontrado na literatura (CARDOSO et al., 2011; PEREIRA FILHO, 2002; PEREIRA et al., 2005; CAMPOS et al., 2010). Os índices médios de espiga foram: 0,99; 1,25; 0,97; 1,02 e 0,96, respectivamente para T1; T2; T3; T4 e T5 (tabela 3). Apesar de T1 ter conferido um índice acima de 1,2, diferença maior que $22 \%$ para T5 $(0,97)$, o teste estatístico aplicado indicou que não existiu qualquer alteração significativa $(p>0,05)$ para este componente, em fertilizar o híbrido, seja com urina, esterco curtido ou fertilizante químico (NPKS + micronutriente).

No tocante ao diâmetro da espiga sem palha, o tratamento controle (T1) resultou no menor valor, igual a 34,60 mm. Os diâmetros médios das espigas foram iguais a 40,69; 40,96; 42,93 e 44,23 mm, respectivamente para T2; T3; T4 e T5. A aplicação em 1,5 vezes o volume de urina resultou no maior diâmetro, valor superior em $21,8 \%$ à T1 (tratamento controle) e $8 \%$ à T2 (fertilização química). Conforme verificado na tabela 4, apenas $\mathrm{T} 1$, diferiu estatisticamente dos demais tratamentos $(\mathrm{p}<0,05)$.

Gort et al. (2015), utilizando a urina humana como fertilizante para produção de milho, obtiveram diâmetros médios da espiga iguais a 53,3 mm, valores estes próximos aos alcançados neste trabalho. Comparando os resultados com Albuquerque (2008), verificou-se que todos os tratamentos resultaram em valores que podem ser enquadrados como espigas comerciais, uma vez que espigas verdes despalhadas maiores que $3,0 \mathrm{~cm}$ de diâmetro podem ser classificadas como comerciais.

Com exceção de T1 com média de 34,60 mm, todos os tratamentos com urina alcançaram diâmetros médios acima de $40 \mathrm{~mm}$. A média de 44,23 mm para T5 ficou bem próxima às pesquisas de vários autores, como por exemplo, Mata et al. (2010) com valores entre 44,75 e 47,96 mm, ao aplicar diferentes doses de esterco bovino no cultivar híbrido simples DAS655.

O comprimento da espiga também sofreu alterações a partir das diferentes doses de urina. $\mathrm{O}$ maior comprimento foi verificado em T5, com média igual a 16,46 cm, e o menor em T1, com média igual a 13,42 $\mathrm{cm}$, constituindo uma diferença de 18,5\%. Os valores máximos variaram entre $22 \mathrm{~cm}$, para T1 e $24 \mathrm{~cm}$, para T3. Pelo teste estatístico empregado, não existe diferença em aumentar as doses (T3, T4 e T5), nem de utilizar o fertilizante químico (T2) (tabela 4).

De forma análoga à altura da planta, o comprimento da espiga se comportou de forma linear quando se incorporou $50 \%$ a mais de urina com um coeficiente (R2) igual a 0,948, obedecendo à equação y $=0,2769 x$ $+13,857$. A diferença relativa entre T5 ( 1,5 vezes a dose de urina) e T4 (metade da dose de urina) foi de 10,1\%. Apenas T5 e T3 apresentaram valores acima do comprimento médio comercial informado por Albuquerque (2008) que é de $15 \mathrm{~cm}$ para o milho verde. Combinando as duas principais características mais valorizadas comercialmente, verifica-se que apenas os tratamentos com urina, T3 e T5, foram capazes de atender ambas, com um diâmetro médio da espiga acima de 3,0 cm e um comprimento acima de $15 \mathrm{~cm}$ (tabela 4).

Resultados similares também foram reportados por Mata et al. (2010) variando a taxa de esterco bovino de 0 a 60 t.ha $^{-1}$. Os comprimentos médios variaram de 14,03 a 15,96 cm, e o aumento da dose de esterco não proporcionou qualquer efeito significativo sobre esta característica. De forma geral, os comprimentos médios estão equivalentes com os valores observados em diversos estudos no país, 
corroborando o potencial do uso da urina no favorecimento de nutrientes essenciais ao crescimento da espiga do milho.

Já Bremm et al. (2012) observaram que a adição do lodo de esgoto ao solo promoveu uma resposta significativa para o desenvolvimento das plantas, com valores de comprimento da espiga bem acima dos encontrados neste estudo, com médias de 17,7 a 19,0 cm, dependendo da dose aplicada. Esta diferença de mais de $13,4 \%$, entre os resultados de Bremm et al. (2012) e desta pesquisa, pode estar relacionada à maior disponibilidade de fósforo proporcionada pelo lodo de esgoto, ao aumento de cargas negativas devido à alta

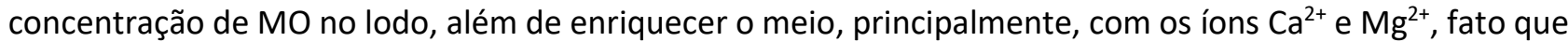
contribui para o aumento da CTC (capacidade de troca de cátions) e saturação por bases, bem como dos fatores já citados como condições climáticas e genótipo da cultivar (MELO et al., 1994; BARBOSA et al., 2007; GALDOS et al., 2004).

No entanto, o uso de lodo de esgoto difere-se da urina, principalmente, quanto aos riscos ambientais e à saúde pública já relatados por diversos autores (SOUZA et al., 2012; MARTINS et al., 2003; GOMES et al., 2006), como a contaminação por micro-organismos patógenos, acúmulo de metais pesados no solo e a interação destes contaminantes nos ecossistemas e assim subsequente entrada na cadeia alimentar. Além disso, a urina pode ser obtida na própria residência, diferentemente do lodo de esgoto que se concentra em locais distantes da real aplicação, se a ótica da agricultura familiar é pensada.

Os pesos médios das espigas sem palha, em ordem crescente, foram iguais a $81,1 \mathrm{~g}$, para T1; 118,3g, para T4; 127g, para T2; 141,3g, para T3 e 160,1g, para T5. Estatisticamente, T3 e T5, e T4 e T2 não diferiram entre si. Todavia, T1 alcançou a menor produtividade, diferindo dos demais tratamentos (tabela 4). Logo, o peso das espigas variou conforme o tipo de adubação (química ou urina) e quanto ao volume de urina aplicado.

Embora o milho de maior peso $(364,5 \mathrm{~g})$ tenha sido originado do tratamento T2 (NPKS), a aplicação de urina, ou seja, os tratamentos T3 e T5 desenvolveram maiores produtividades. O menor milho, em termos de peso, originou-se também desse mesmo tratamento (T2), e essa tamanha variação resultou no maior desvio-padrão no valor de 81,1. Acredita-se que uma praga desenvolvida em seis plantas desse tratamento seja a possível explicação para tal fato, reduzindo, assim, sua produtividade.

Observa-se que quanto maior o volume de urina, melhor é a resposta da planta em relação ao peso da espiga de milho, considerando, é claro, que a maior taxa de urina aplicada correspondeu a $90 \mathrm{~kg} . \mathrm{ha}^{-1}$. Semelhantemente às variáveis, altura da planta e comprimento, o peso das espigas se comportou de forma linear quando se incorporou $50 \%$ a mais de urina, com um coeficiente (R2) igual a 0,997, obedecendo à equação $y=6,9667 x+98,1$

Todas as pesquisas, até então realizadas, corroboram quanto ao ganho de crescimento e produção do uso da urina na agricultura, quando se compara com tratamentos controle, ou seja, sem adição de fertilizantes químicos. Morgan (2005) observou um ganho de mais de $43 \%$ no peso do milho fertilizado com urina, bastante próximo do obtido nesta pesquisa. Pradhan et al. (2009) alcançaram resultados significativos com o uso da urina acrescida de cinzas, proporcionando aumento de até $3 \%$ na produtividade do tomate. 
Utilizando o repolho, como cultura teste, Pradhan et al. (2007) verificaram que a urina possibilita um acréscimo de $256 \mathrm{~kg}$ deste vegetal por parcela de $90 \mathrm{~m}^{2}$, em comparação com a não fertilização. Guzha et al. (2005) constaram que a urina seria capaz de dobrar a produtividade do milho quando não se aplica qualquer fertilizante. De forma geral, os dados obtidos a partir do experimento no Ceará corroboram com os ganhos de produtividade alcançados com o uso da urina por diversos autores com pesquisas em vários países.

Entretanto, não se esperava que T5 fosse propiciar um aumento maior que $20 \%$ no peso do milho, em comparação com o fertilizante químico (T2). Da mesma forma, alguns estudos, também, já verificaram diferenças de tamanha magnitude. Germer et al. (2011), realizando pesquisas em Gana durante os anos de 2006, 2007 e 2009, reportaram acréscimos na produtividade de sorgo, fertilizado com urina, em 3,5 vezes, quando comparado com a fertilização química. Dentre as principais justificativas para tais resultados são: possível menor perda de amônia por volatilização nos tratamentos com urina do que nos tratamentos que receberam fertilizante químico (GERMER et al., 2011) e a presença de diversos elementos essenciais (macro e micro) na urina em comparação com os fertilizantes químicos.

De forma similar, Guzha et al. (2005) verificaram que a produtividade foi altamente afetada com o uso de urina em comparação ao tratamento controle (sem fertilizantes). Estes autores concluíram, ainda, que os melhores desempenhos são alcançados quando os agricultores utilizam a combinação de composto fecal e urina, como condicionador do solo e fertilizante natural.

Gort et al. (2015) também obtiveram valores de produtividade, expressivamente, maiores para o tratamento fertilizado com urina humana. Enquanto a produtividade proporcionada pelo tratamento controle (sem fertilizante) alcançou apenas 1,03 tha ${ }^{-1}$, a produtividade referente ao tratamento com urina humana chegou a 4,80 t.ha-1. Quando Pradhan et al. (2009) compararam a aplicação de fertilizante químico e urina pura, a produtividade de frutos entre esses tratamentos não surtiu efeito expressivo, porém, com relação ao tratamento controle (sem fertilizantes) foi verificado um acréscimo de 3 vezes.

Provavelmente, a baixa produtividade proporcionada pela fertilização química (T2), comparada à T4 ( 0,5 vezes a dose da urina), foi ocasionada por uma praga desenvolvida em seis plantas deste tratamento, reduzindo, assim, de forma significativa, sua produtividade. Após a verificação da praga, identificada como a lagarta-do-cartucho (Spodoptera frugiperda Smith), foi aplicado de imediato o defensivo agrícola Lannate ${ }^{\circledR}$ $\mathrm{BR}$, com ingrediente ativo ((S-metil-N-(metilcarbamoil)-oxi)-tioacetimidato) (METHOMYL), porém as plantas não conseguiram se recuperar até o final do plantio.

De acordo com Werle et al. (2011), a lagarta-do-cartucho (Spodoptera frugiperda Smith) é a principal praga da cultura do milho no Brasil. Esta praga, também, causou prejuízos ao andamento desta pesquisa e influenciou, diretamente, os resultados alcançados, principalmente, quanto à produtividade de espigas do T2 (NPKS + micronutrientes).

Entretanto, após o término do experimento e feito um levantamento observacional, verificou-se que apenas as plantas que não receberam a urina como fertilizante foram acometidas por tal praga.

Já existem publicações que consideram a urina como fertiprotetores, ou seja, produtos que fornecem nutrientes às plantas, influenciando positivamente no processo metabólico das mesmas, além de 
contribuírem para o controle de parasitas (PESAGRO-RIO, 2002; FERNANDES et al., 2008). Em uma pesquisa por meio de entrevistas semiestruturadas, agricultores orgânicos apontaram o uso da urina no controle da mosca-branca (Bemisia argentifolii) e oídio do tomateiro (SOUSA et al., 2012).

Portanto, duas hipóteses devem ser levantadas: (1) a ocorrência da praga apenas nas plantas fertilizadas com NPKS se deve ao acaso e (2) a urina é um potencial praguicida à lagarta-do-cartucho. Vários fatores podem influenciar o rendimento da cultura do milho como o potencial produtivo do híbrido, as condições climáticas, a população de plantas, e condições nutricionais e fitossanitárias em um agroecossistema (DOURADO NETO et al., 2003). Sabe-se que a exigência do nitrogênio pela cultura do milho aumenta quando se espera obter maiores índices de produtividade. Devido aos altos preços dos fertilizantes nitrogenados e ao baixo poder de compra dos agricultores nos países em desenvolvimento, grande parte das lavouras de milho é conduzida sobre condições de deficiência de nitrogênio (BÄNZIGER et al., 1997).

Diante destes cenários e em conformidade com Karak et al. (2011), é possível fazer uso da urina como uma fonte alternativa de nutrientes, beneficiando diretamente os pequenos e médios agricultores, além de impactar positivamente no meio ambiente e na economia local. O alcance do sucesso desta façanha dependerá da criação de novas áreas da pesquisa científica e posterior regulamentação de normas e leis pelo poder público, por meio da integração holística de profissionais das áreas de biologia, agronomia e engenharias.

\section{CONCLUSÕES}

O estudo alerta para o risco de salinização do solo com a aplicação da urina, exigindo um correto manejo da irrigação da cultura, de maneira a diminuir e controlar a concentração de alguns constituintes, como o sódio e cloretos. Do ponto de vista experimental, o presente estudo evidenciou resultados promissores acerca da utilização de urina humana na fertilização de Zea mays, indicando um potencial da aplicação deste excreta na agricultura com intuito de reduzir o consumo ou até em alguns casos substituir o uso de fertilizantes químicos. O peso das espigas variou conforme o tipo de adubação (química ou urina) e quanto ao volume de urina aplicado, ocorrendo efeito entre aplicar urina na taxa de 1,5 ou 1 e aplicar urina na taxa de 0,5 ou adubo químico. A urina se mostrou como um potencial praguicida à lagarta-do-cartucho, pois nenhuma das plantas que recebeu este tratamento foi acometida por tal praga, a qual prejudicou a produtividade do tratamento com NPKS. Contudo, tal efeito merece ser melhor investigado.

AGRADECIMENTOS: Os autores agradecem ao Laboratório de Saneamento (Labosan), ao CNPq (Projeto 560014/2008-0) e à CAGECE pelo apoio financeiro.

\section{REFERÊNCIAS}

ALBUQUERQUE, C. J. B.; VON PINHO, R. G.; SILVA, R.. Produtividade de híbridos de milho verde experimentais e comerciais. Bioscience Journal, Uberlândia, v.24, n.2, p.6976, 2008.
ALMEIDA, M. L.; MEROTTO JÚNIOR, A.; SANGOI, L.; ENDER, M.; GUIDOLIN, A. F.. Incremento na densidade de plantas: uma alternativa para aumentar o rendimento de grãos de milho em regiões de curta estação estival de crescimento. 
Ciência Rural, Santa Maria, v.30, n.1, p.23-29, 2000. DOI: http://dx.doi.org/10.1590/S0103-84782000000100004

BÄNZIGER, M.; BETRAN, F. J.; LAFFITE, H. R.. Efficiency of high-nitrogen selection environments for improving maize for low-nitrogen target environments. Crop Science, Washington, v.37, n.4, p.1103-1109, 1997. DOI: http://10.2135/cropsci1997.0011183X003700040012x

BARBOSA, G. M. C.; TAVARES FILHO, J.; BRITO, O. R.; FONSECA, I. C. B.. Efeito residual do lodo de esgoto na produtividade do milho safrinha. Revista Brasileira de Ciências do Solo, Viçosa, v.31, n.3, p.601-605, 2007. DOI: http://dx.doi.org/10.1590/S0100-06832007000300020

BRASIL. Ministério da Agricultura. Levantamento exploratório: reconhecimento de solos do Estado do Ceará. Rio de Janeiro: MAPA/SUDENE, 1973.

BREMM, R. R. R.; DAMASCENO, S. G.; SECCO, D.; VILAS BOAS, M. A.; TORRES, D. G. B.; MEES, J. B. R.; KUMMER, L.. Potencial de uso de lodo de esgoto na cultura do milho em latossolo argiloso no oeste do Paraná. Revista Brasileira de Ciências Ambientais, Rio de Janeiro, n.23, p.17-24, 2012.

CAMPOS, M. C. C, V SILVA, V. A. da; CAVALCANTE, I. H. L. BECKMANN, Z.. Produtividade e características agronômicas de cultivares de milho safrinha sob plantio direto no Estado de Goiás. Revista Acadêmica Ciências Agrárias e Ambientais, Curitiba, v.8, n.1, p.77-84, 2010.

CARDOSO, M. J.; RIBEIRO, V. Q.; MEL O, F. B.. Performance de cultivares de milho-verde no município de Teresina, Piauí. Teresina: Embrapa, 2011.

CASTRO, R. S.. Rendimentos de Espigas Verdes e de Grãos de Cultivares de Milho após a Colheita da Primeira Espiga como Minimilho. Tese (Doutorado em Fitotecnia Área de Concentração Agricultura Tropical) - Universidade Federal Rural do Semiárido, Mossoró, 2010.

CRUZ, J. C.. Cultivo do milho. Versão Eletrônica. 7 ed. Sete Lagoas: Embrapa, 2011.

DOURADO NETO, D. D.; PALHARES, M.; VIEIRA, P. A.; MANFRON, P. A.; MEDEIROS, S. L. P.; ROMANO, M. R.. Efeito da população de plantas e do espaçamento sobre a produtividade de milho. Revista Brasileira de Milho e Sorgo, Sete Lagoas, v.2, n.3, p.63-77, 2003. DOI: http://dx.doi.org/10.18512/1980-6477/rbms.v2n3p63$\underline{77}$

DUARTE, S. L.; PEREIRA, C. A.; ALMEIDA, L. C. F.; TAVARES, M.; REIS, E. A.. Análise das variáveis dos custos de produção do milho no período da safra. In: SEGET SIMPÓSIO DE EXCELÊNCIA EM GESTÃO E TECNOLOGIA, 7. Anais. Rio de Janeiro: Associação Educacional Dom Bosco, 2010.

EMBRAPA. Sistema Brasileiro de Classificação de Solos. 2 ed. Rio de Janeiro: Embrapa, 2006.

GALDOS, M. V.; MARIA, I. C.; CAMARGO, O. A.. Atributos químicos e produção de milho em um Latossolo Vermelho eutroférrico tratado com lodo de esgoto. Revista Brasileira de Ciência do Solo, Viçosa, v.28, n.3, p.569-577, 2004. DOI: http://dx.doi.org/10.1590/\$0100-06832004000300017
GERMER, J.; ADDAIB, S.; SAUERBORNA, J.. Response of grain sorghum to fertilisation with human urine. Field Crops Research, Amsterdã, v.122, n.3, p.234-241, 2011. DOI: http://10.1016/j.fcr.2011.03.017

GOMES, S. B. V.; NASCIMENTO, C. W. A.; BIONDI, C. M.; ACCIOLY, A. M. A.. Distribuição de metais pesados em plantas de milho cultivadas em Argissolo tratado com lodo de esgoto. Ciência Rural, Santa Maria, v.36, p.1689-1695, 2006. DOI: http://dx.doi.org/10.1590/S010384782006000600004

GORT, D. G.; AGOSTINO, N. J.; KARZAO, A.; TOMÉ, A. V.. Uso de fertilización orgánica basada en orina humana en el cultivo del maíz (Zea mays L.). Agrisost, Havana, v.21, p.9-7, 2015.

GIZ. Gesellschaft für internationale Zusammenarbeit. Worldwide list of $\mathbf{3 2 4}$ documented Ecosan projects by various organizations. Eschoborn, 2012.

GUZHA, E.; NHAPI, I.; ROCKSTRÖM, J.. An assessment of the effect of human faeces and urine on maize production and water productivity. Physics and Chemistry of the Earth, Londres, v.30, n.8, p.840-845, 2005. DOI: http://10.1016/j.pce.2005.08.028

HEINONEN-TANSKI, H.; SJÖBLOM, A.; FABRITIUS, H.; KARINEN.P.. Pure human urine is a good fertilizer for cucumbers. Bioresource Technology, Amsterdã, v.98, n.11, p.214-217, 2007. DOI:

http://10.1016/j.biortech.2005.11.024

JÖNSSON, H.; STINZING, A. R.; VINNERÅS, B.; SALOMON, E.. Guidelines on the Use of Urine and Faeces in Crop Production. Suécia: Stockholm Environment Institute, 2004.

KAPPES, C.. Desempenho de Híbridos de Milho em Diferentes Arranjos Espaciais de Plantas. Dissertação (Mestrado em Agronomia) - Faculdade de Engenharia, Ilha Solteira, 2010.

KARAK, T.; BHATTACHARYYA, P.. Human urine as a source of alternative natural fertilizer in agriculture: $A$ flight of fancy or an achievable reality. Resource, Conservation and Recycling, Amsterdã, v.55, n.4, p.400-408, 2011. DOI: http://10.1016/j.resconrec.2010.12.008

KASSA, K.; MEINZINGER, F.; ZEWDIE, W.. Experiences from the use of urine in Arba Minch, Ethiopia. Sustainable Sanitation Practice Journals, Issue 3, 2010.

MARCHÃO, R. L.; BRASIL, E. M.; DUARTE, J. B.; GUIMARÃES, C. M.; GOMES J. A.. Densidade de plantas e características agronômicas de híbridos de milho sob espaçamento reduzido entre linhas. Pesquisa Agropecuária Tropical, Goiânia, v.35, n.2, p.93-101, 2005.

MARTINS, A. L. C.; BATAGLIA, O. C.; CAMARGO, O. A.; CANTARELLA, H.. Produção de grão e absorção de $\mathrm{Cu}, \mathrm{Fe}, \mathrm{Mn}$ e $\mathrm{Zn}$ pelo milho em solo adubado com lodo de esgoto, com e sem calcário. Revista Brasileira de Ciência do Solo, Viçosa, v.27, n.3, p.563-574, 2003. http://dx.doi.org/10.1590/S0100$\underline{06832003000300018}$

MATA, J. F.; DA SILVA. J. C.; RIBEIRO, J. F.; AFFÉRRI, F. S.; VIEIRA, L. M.. Produção de milho híbrido sob doses de 
esterco bovino, Pesquisa Aplicada \& Agrotecnologia, Curitiba, v.3, n.3, p.125-134, 2010.

MELO, W. J.; MARQUES, M. O.; SANTIAGO, G.. Efeito das doses crescentes de lodo de esgoto sobre frações da matéria orgânica e CTC de um Latossolo cultivado com cana-deaçúcar. Revista Brasileira de Ciência do Solo, Viçosa, v.18, p.449-455, 1994.

MORGAN, P.. Ecological Sanitation in Southern Africa: Many approaches to a varied need. Estocolmo, 2005.

MORGAN, P.. Experiments using urine and humus derived from ecological toilets as a source of nutrients for growing crops. 3rd. Kyoto: World Water Forum, 2003.

PEREIRA FILHO, I. A.; PEREIRA FILHO, I. A. C.; GAMA, E. E. G. E.. Cultivares de milho para o consumo verde. Sete Lagoas: Embrapa, 2002.

PRADHAN, S. K.; HOLOPAINEN, J. K.; HEINONEN-TANSKI, H.. Stored Human Urine Supplemented with Wood Ash as Fertilizer in Tomato (Solanum lycopersicum) Cultivation and Its Impacts on Fruit Yield and Quality. Journal of Agricultural and Food Chemistry, Washington, v.57, n.16, p.7612-7617, 2009. DOI: http://10.1021/jf9018917

PRADHAN, S. K.; NERG, A. M.; SJOBLOM, A.; HOLOPAINEN, J. K.; HEINONEN-TANSKI, H.. Use of Human Urine Fertilizer in cultivation of Cabbage (Brassica oleracea): Impact on chemical, Microbial, and Flavor Quality. Journal of Agricultural and Food Chemistry, Estocolmo, v.55, n.21, p.8657-8863. 2007. DOI: http://doi.org/10.1021/if0717891

RICHERT, A.; GENSCH, R.; JOENSSON, H.; STENSTROEM, T.A.; DAGERSKOG, L.. Practical Guidance on the Use of Urine in Crop Production. Estocolmo: Stockholm Environment Institute (SEI), 2010.
SHAW, R.. The Use of Human Urine as Crop Fertilizer in Mali, West Africa. Michigan, 2010.

SHRESTHA, D.; SRIVASTAVA, A.; SHAKYA, S. M.; KHADKA, J.; ACHARYA, B. S.. Use of compost supplemented human urine in sweet pepper (Capsicum annuum L.) production. Scientia Horticulturae, Amsterdã, v.158, n.1, p.8-12, 2013. DOI: http://10.1016/j.scienta.2013.01.022

SILVA, D. M. F.; KHAN, A. S.; LIMA, P. V. P. S.. Produção de milho híbrido no Estado do Ceará: aspectos tecnológicos, competitivos, geração de emprego e renda. Revista de Economia e Sociologia Rural, Curitiba, v.44, n.1, p.119-146, 2006. DOI: http://dx.doi.org/10.1590/S010320032006000100006

SOUZA, R. A. S.; BISSANI, C. A.; TEDESCO, M. J.; FONTOURA, R. C.. Extração sequencial de zinco e cobre em solos tratados com lodo de esgoto e composto de lixo. Química Nova, São Paulo, v.35, n.2, p.308-314, 2012.

TOZETTI, A. D.; BILLIA, R. C.; SILVA, C.; CERVIGNI, G.; GOMES, O. M. T.. Avaliação de progênies de milho na presença e ausência de adubo. Revista Científica Eletrônica de Agronomia, Garça, v.6, n.5, p.6-10, 2004.

WERLE, A. J. K.; NICOLAY, R. J.; SANTOS, R. F.; BORSOI, A.; SECCO, D.. Avaliação de híbridos de milho convencional e transgênico (Bt), com diferentes aplicações de inseticida em cultivo safrinha. Revista Brasileira de Tecnologia Aplicada nas Ciências Agrárias, Guarapuava, v.4, n.1, p.150-168, 2011.

WHO. World Health Organization. Guidelines for the Safe Use of Wastewater, Excreta and Greywater: Policy and Regulatory Aspects. Geneva, 2006.

A CBPC - Companhia Brasileira de Produção Científica (CNPJ: 11.221.422/0001-03) detém os direitos materiais desta publicação. Os direitos referem-se à publicação do trabalho em qualquer parte do mundo, incluindo os direitos às renovações, expansões e disseminações da contribuição, bem como outros direitos subsidiários. Todos os trabalhos publicados eletronicamente poderão posteriormente ser publicados em coletâneas impressas sob coordenação da Sustenere Publishing, da Companhia Brasileira de Produção Científica e seus parceiros autorizados. Os (as) autores (as) preservam os direitos autorais, mas não têm permissão para a publicação da contribuição em outro meio, impresso ou digital, em português ou em tradução. 